\title{
Evidence based practice: clinicians' use and attitudes to near patient testing in hospitals
}

\author{
T A Gray, D B Freedman, D Burnett, A Szczepura, C P Price
}

Department of Clinical Chemistry, Northern General Hospital, Sheffield

T A Gray

\section{Department of} Chemical Pathology, Luton and Dunstable Hospital NHS Trust, Luton

D B Freedman

Department of Clinical

Biochemistry,

St Albans City

Hospital, St Albans

D Burnett

\section{Centre for Health}

Service Studies,

Warwick Business

School, Coventry

A Szczepura

Department of Clinical Biochemistry,

The London Hospital

Medical College,

London

C P Price

Correspondence to:

Dr T A Gray, Department of Clinical Chemistry,

Northern General Hospital,

Herries Road,

Sheffield S5 7AU.

Accepted for publication 16 July 1996

\begin{abstract}
Aim-To survey the use made of laboratory services for urgent tests and clinicians' attitudes to near patient testing. Methods-A questionnaire was sent to clinicians working in acute hospitals within Trent and North West Thames Regions.

Results-197 replies were received. Most demand came from intensive care units. Overall, clinicians requested a median of six urgent tests a day. Blood glucose and dip stick urine testing were the most commonly performed bedside tests, but $41 \%$ of clinicians did not use ward testing. The most frequently cited indication for bedside testing was the need for speed. $85 \%$ of clinicians trusted results obtained in their central hospital laboratory, but there was an almost equal division between those who did (34\%) and those who did not $(38 \%)$ trust the results from near patient testing. A slightly larger proportion indicated they would accept responsibility (44\%) for results obtained on the ward than would not (35\%). Most staff indicated that better transport to the laboratory would remove the need for near patient testing.

Conclusions-Clinicians have demonstrated an apparent need for rapid response testing but there is a strong preference for rapid transport systems and central laboratory analysis rather than bedside testing as a solution to this problem. There is a need to investigate the clinical and cost-effectiveness of near patient testing as a solution to rapid response testing.

(F Clin Pathol 1996;49:903-908)
\end{abstract}

Keywords: near patient testing, rapid response testing, survey.

It is over 10 years since Marks suggested that advances in the technology of near patient testing may bring biochemistry nearer the patient, ${ }^{12}$ but it is only in the past few years that the technology has become sufficiently advanced for that to be true for more than one or two tests, such as blood glucose and gases. Companies are now marketing a much wider range of bedside tests not just in biochemistry but also for most other pathology disciplines, which could previously only be undertaken in the hospital laboratory. At the same time, hospitals are coming under increasing pressure to shorten patients' stay and are looking for ways of obtaining pathology test results more rapidly to reduce delays between diagnosis and treatment. The reduction in junior doctors' hours also creates pressure for a more rapid turnround of pathology results as junior medical staff have to cover more patients in order to deliver care within their hours and have less time to follow up on requests to the laboratory as they tend to have more fragmented contact with patients. These pressures are creating renewed interest in near patient testing and rapid sample transport as strategies to decrease turnround time for pathology tests. Some hospitals have introduced the concept of patient focused care $^{3}$ which involves, among other changes, the use of multi-skilled staff to reduce the number involved in delivering direct patient care. By operating bedside testing on a patient focused unit, such staff may be able to provide pathology results more directly and rapidly. However, the demand for near patient testing from hospital clinicians has not been quantified and it is not clear whether a wholesale move towards ward based testing would be welcomed. A working party of the Standing Advisory Committee in Chemical Pathology of the Royal College of Pathologists was set up to examine this question. The Committee undertook to survey the demand for urgent laboratory tests and explore clinicians' views of near patient testing.

\section{Methods}

A questionnaire was compiled to measure the extent of and demand for near patient testing and urgent laboratory services. The questionnaire was piloted in a large district general teaching hospital and modified in response. The modified questionnaire (fig 1) was circulated to pathology clinical directors or equivalent in the former Trent and North West Thames Regions through regional Chemical Pathology Panels. The pathology directors were requested to circulate the questionnaire to all consultants in clinical specialties in the acute hospitals they served. Responses were collected locally and passed to the authors for analysis. Responses provided to question 7 which asked for agreement or disagreement with statements to be indicated on a graduated scale of 1 to 5 were tested for equality across the scale using the Kolmogorov-Smirnov 1 sample test. Differences in response between questions were tested using the McNemar test after elimination of those indicating no preference. Each pathology department in hospitals from which a response was received was asked subsequently whether there was a tube transport system for pathology samples serving the laboratory. 
Royal College of Pathologists Standing Advisory Committee on Chemical Pathology Near Patient

Testing Working Party

Questionnaire on near patient testing

Specialty.......................................................... Hospital

URGENT LABORATORY TESTS

1 Please list the urgent tests that you and your Junior Staff currently request from the hospital Pathology laboratories from all Pathology disciplines and please estimate the number requested on average each day. In addition, please indicate the number (if any) of each test that is performed on the ward or at the bedside.

\begin{tabular}{|l|l|l|l|}
\hline \multicolumn{2}{|l|}{ Urgent laboratory tests } & \multicolumn{2}{l|}{ Ward/bedside tests } \\
\hline Test & No per day & Test & No performed per day \\
\hline & & & \\
\hline
\end{tabular}

2 Please indicate what you feel is an acceptable turnround time for urgent tests from the laboratory and estimate the current laboratory turnround time for these tests. Acceptable time .................................. Estimate of current turnround time ......................

3 Please list any other tests currently not available as urgent or bedside tests that you would like to be able to request on a fast turnround basis from the laboratory or have available as a bedside test (if the technology were available?)

\begin{tabular}{|l|l|l|}
\hline Test & $\begin{array}{l}\text { Estimated No of tests required from laboratory urgently each } \\
\text { day }\end{array}$ & Estimated No of bedside tests required each day \\
\hline & & \\
\hline & & \\
\hline
\end{tabular}

4 What are the most important indications for tests to be performed at the bedside or on the ward rather than asking for an urgent test to be performed in the laboratory?

Please indicate which staff group usually carries near patient tests on your wards and which staff group you think is most appropriate for this task? (please tick).

\begin{tabular}{|l|l|l|}
\hline & $\begin{array}{l}\text { Carries out tests currently (please tick } \\
\text { only one) }\end{array}$ & $\begin{array}{l}\text { Most appropriate for the task (please tick only } \\
\text { one) }\end{array}$ \\
\hline Doctors & & \\
\hline Nurses & & \\
\hline ODA & & \\
\hline MLSO & & \\
\hline Other (please specify) & & \\
\hline
\end{tabular}

6 Do you generally trust the results of tests carried out on the wards or at the bedside for the care of your patients? YES / NO Do you ask for the results of near patient testing to be checked out in the laboratory? NO/ONLY IF ABNORMALFOR QUALITY CONTROL PURPOSES/REGULARLY

7 Please indicate if you agree or disagree with the following statements. Please score the statements on a scale of 1 to 5 where 1 is strongly agree and 5 is strongly disagree.

Near patient testing saves Medical Staff time

Near patient testing should be part of the Nurses' duties

Junior hospital Doctors should be looking after patients not doing laboratory tests

Near patient testing improves outcome for patients

I only ask the hospital laboratory to check near patient test results if the result is abnormal

Near patient testing saves Nursing staff time

I have full confidence in the local laboratory results

In future I see most of my urgent tests being carried out at the bedside or on the ward

I am happy to accept responsibility for accuracy of near patient tests carried out on my authority

Rapid laboratory response means I don't need near patient testing

I trust the results of near patient testing to guide patient care without further

laboratory checks

Staff who undertake near patient tests on my wards have been appropriately

trained for the performance of this function

Staff who undertake near patient testing on my wards are regularly monitored in their performance of this function

If I had a more rapid specimen transport system and computer links for results, I would not need near patient testing

The biggest problem with obtaining an urgent laboratory result is getting the sample to the laboratory

I would prefer to be telephoned with an urgent result rather than look it up on a computer

\begin{tabular}{|c|c|c|c|c|}
\hline \multicolumn{4}{|c|}{$\begin{array}{l}\text { Strongly } \\
\text { agree }\end{array}$} & \multirow{2}{*}{$\begin{array}{l}\text { Strongly } \\
\text { disagree } \\
5\end{array}$} \\
\hline 1 & 2 & 3 & 4 & \\
\hline 1 & 2 & 3 & 4 & 5 \\
\hline 1 & 2 & 3 & 4 & 5 \\
\hline 1 & 2 & 3 & 4 & 5 \\
\hline 1 & 2 & 3 & 4 & 5 \\
\hline 1 & 2 & 3 & 4 & 5 \\
\hline 1 & 2 & 3 & 4 & 5 \\
\hline 1 & 2 & 3 & 4 & 5 \\
\hline 1 & 2 & 3 & 4 & 5 \\
\hline 1 & 2 & 3 & 4 & 5 \\
\hline 1 & 2 & 3 & 4 & 5 \\
\hline 1 & 2 & 3 & 4 & 5 \\
\hline 1 & 2 & 3 & 4 & 5 \\
\hline 1 & 2 & 3 & 4 & 5 \\
\hline 1 & 2 & 3 & 4 & 5 \\
\hline 1 & 2 & 3 & 4 & 5 \\
\hline & & & & that you \\
\hline
\end{tabular}

8 Please add any further comments about the urgent laboratory service available to you, the urgent laboratory service that you

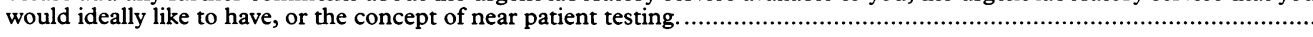
.

Thank you very much for taking the time to complete this questionnaire

Figure 1 Modified questionnaire circulated to pathology clinical directors or equivalent in the former Trent and North West Thames Regions. 
Table 1 Clinicians' estimates of daily requirement for urgent tests

\begin{tabular}{lllll}
\hline Test & Mean & Median & Maximum & $\begin{array}{l}\text { Consultants } \\
\text { responding (\%) }\end{array}$ \\
\hline Urea and electrolytes & 6.7 & 4 & 50 & 81 \\
Full blood count & 7.6 & 4 & 50 & 73 \\
Glucose & 6.0 & 3.5 & 50 & 38 \\
Coagulation tests & 2.9 & 1 & 30 & 29 \\
Cross match & 3.4 & 2 & 20 & 23 \\
Blood gases & 8.2 & 2 & 100 & 21 \\
Calcium & 3.8 & 1 & 40 & 16 \\
Cardiac enzymes & 4.1 & 3 & 12 & 16 \\
Amylase & 3.1 & 1 & 20 & 14 \\
Urine microbiology & 4.1 & 2 & 20 & 13 \\
Liver function tests & 5.0 & 5 & 12 & 12 \\
CSF examination & 1.0 & 1 & 4 & 12 \\
Paracetamol/salicylate & 1.7 & 1 & 10 & 9 \\
Pregnancy test/hCG & 2.6 & 1 & 10 & 7 \\
ESR & 1.6 & 1 & 6 & 5 \\
Bilirubin & 4.4 & 2 & 10 & 4 \\
Osmolality & 1.5 & 1.5 & 1 & 1 \\
Albumin & 0.5 & 1
\end{tabular}

CSF = cerebrospinal fluid; $\mathrm{ESR}=$ erythrocyte sedimentation rate.

Table 2 Urgent tests not available but thought useful

\begin{tabular}{lll}
\hline Test & $\begin{array}{l}\text { Estimated mean } \\
\text { daily requirement }\end{array}$ & $\begin{array}{l}\text { Consultants } \\
\text { responding (\%) }\end{array}$ \\
\hline Cardiac enzymes & 6.7 & 6 \\
Lactate & 3.3 & 3 \\
Coagulation tests & 2.8 & 3 \\
C-reactive protein & 5.3 & 2 \\
Pregnancy test/hCG & 4 & 2 \\
\hline
\end{tabular}

\section{Results}

In total, 197 consultants provided evaluable responses from 27 of 35 hospitals. They represented a wide range of clinical specialties, including anaesthetics and intensive care, accident and emergency, general and specialist medicine, general and specialist surgery, obstetrics and gynaecology, and paediatrics, including neonatal intensive care. The estimated response from the various hospital clinicians varied from $1 \%$ to about $30 \%$. The questionnaire was circulated to consultants in clinical specialties but it is likely that only those that use the laboratories or near patient testing made a return; however, there were few null responses and these were excluded.

\section{URGENT LABORATORY TESTS}

The urgent tests requested most frequently from the laboratory were urea and electrolytes ( $81 \%$ of replies, with a median of four requests daily) and full blood counts (73\% of replies, with a median of four requests daily). The distribution of the demand for urgent tests was skewed with $10 \%$ of the consultants not requesting urgent laboratory tests on a daily basis; overall, a mean of 21.6 tests was requested daily but the median was only six. The frequency of requesting of urgent tests and the number of tests per requesting

Table 3 Clinicians' estimates of number of near patient tests performed each day

\begin{tabular}{lllll}
\hline Test & Mean & Median & Maximum & $\begin{array}{l}\text { Consultants } \\
\text { responding (\%) }\end{array}$ \\
\hline Glucose & 13.8 & 8 & 100 & 43 \\
Urine stick test & 11.9 & 6 & 100 & 26 \\
Blood gases & 11.8 & 6 & 100 & 24 \\
Urea and electrolytes & 6.9 & 4 & 50 & 8 \\
Pregnancy test/hCG & 3.9 & 3 & 10 & 7 \\
Coagulation tests & 11.8 & 12 & 30 & 3 \\
Faecal occult blood & 3 & 1 & 5 & 1 \\
Cardiac enzymes & 3.5 & 3 & 15 & 1 \\
\hline
\end{tabular}

consultant are shown in table 1. Additional tests available on an urgent basis in some hospitals included: fine needle aspiration cytology, various microbiological examinations (often unspecified), HIV tests, drug concentrations (unspecified), lactate, cortisol, C-reactive protein and uric acid estimation, Kleihauer and sickle tests.

The turnround times deemed acceptable for urgent tests varied from seven minutes to one day and the clinician's estimation of the actual time taken varied between the same times. The median time clinicians required for turnround was 60 minutes with modal values at 30 and 60 minutes, which represented over $50 \%$ of responses. Their estimate of the actual time taken had a median and modal value of 60 minutes. Just over half of the laboratories $(53 \%)$ provided urgent results within the time required by the clinicians but in $8 \%$ of cases the laboratory apparently took more than two hours longer to report than the clinicians expected.

Tests which were not available at some sites but which were required urgently from the laboratory by more than one respondent are given in table 2 . Other tests listed singly which consultants considered would be useful included sickle tests, chloride, fine needle aspirations cytology, HIV tests, urine protein, myoglobin, oestradiol, prostate specific antigen, urea, sputum microscopy, and the Kleihauer test.

\section{NEAR PATIENT TESTS}

The most commonly performed ward test was blood glucose (43\% of replies, with a median of eight requests daily), and ward urine testing (26\% of replies, with a median of six ward tests daily). Ward based testing was skewed in the same way as urgent requests to the laboratory; $41 \%$ of replies indicated that consultants did not use ward testing. At the other end of the scale, one neonatal unit, in a hospital with an off site laboratory, estimated that over 200 requests were performed on the wards, mainly blood glucose and blood gas measurements. Table 3 indicates the tests that were reported as being carried out on the wards by more than one respondent. Up to $3 \%$ of consultants felt

Table 4 Near patient testing operators

\begin{tabular}{lll}
\hline Staff group & $\begin{array}{l}\text { Who performs tests } \\
\text { (\% responses) }\end{array}$ & $\begin{array}{l}\text { Who should perform } \\
\text { test (\% responses) }\end{array}$ \\
\hline Nurses & 45 & 40 \\
Doctors & 13 & 8 \\
Doctors and nurses & 16 & 12 \\
MLSOs & 4 & 9 \\
Others & 2 & 2 \\
\hline
\end{tabular}

Table 5 Indications for near patient testing

\begin{tabular}{ll}
\hline Indication & Consultants responding (\%) \\
\hline Speed/save time & 31 \\
Immediate patient & 13 \\
management & \\
Convenience/save labour & 11 \\
Blood gases & 8 \\
Glucose & 8 \\
Reliability & 4 \\
Other & 20
\end{tabular}


that cardiac enzymes, coagulation tests, pregnancy tests or human chorionic gonadotrophin (hCG) estimation would be very helpful as ward tests but were not currently available in their hospital. Tests listed by single respondents as being potentially useful included haemoglobin, sickle tests, liver function tests, calcium, HIV, lactate, bilirubin, Kleihauer tests, sputum microscopy, and hepatitis B.

The responses showed that most ward testing is performed by nurses and that the consultant staff consider this appropriate (table 4). Only $4 \%$ of respondents indicated that MLSOs were responsible for undertaking the tests, but another $5 \%$ felt that they should be undertaking these tests. Other staff who undertook tests were operating department assistants.

INDICATIONS FOR NEAR PATIENT TESTING

A wide range of indications for the need for bedside testing were given but by far the commonest response was the need for speed or to save time $(31.5 \%)$ (table 5$)$. The need for a result for immediate patient management was given by $12.7 \%$ of respondents and the convenience of near patient testing was mentioned by $10.7 \%$. Specific tests were mentioned as in table 5 and particular clinical conditions noted by a number of respondents, including renal failure, diabetic problems and acute haemorrhage.

\section{QUALITY OF RESULTS}

The majority $(72 \%)$ of consultants indicated a degree of trust in the result of near patient tests whereas only $9 \%$ did not, but in answer to a later question, only $34 \%$ trusted them sufficiently to use them to guide patient care. However, $26 \%$ of staff did ask for results to be checked by the laboratory if they were abnormal. Only $15 \%$ considered that near patient tests results were checked by the laboratory in order to control the quality of the near patient testing process, although this was routine in $13 \%$ of cases; it was never done according to $16 \%$ of respondents.

Slightly fewer consultants (35\%) agreed they would take responsibility for the results of near patient testing than would not $(44 \%, \mathrm{NS})$ and there was an almost equal split as to whether they did $(34 \%)$ or did not $(38 \%)$ trust near patient tests in the absence of confirmatory laboratory tests. They agreed strongly that they had confidence in the results provided by their laboratory; this was by far the most positive response on the questionnaire, being agreed by $85 \%$ of respondents. Comments in free text emphasised the problems that some staff saw with the quality of near patient testing and the need for continual retraining and monitoring of staff undertaking that task.

THE PLACE FOR NEAR PATIENT TESTING

When asked for their response to particular statements, there was agreement among consultants that near patient testing saved medical ( $50 \%$ agreed, $22 \%$ disagreed), but not nursing staff time, (19\% agreed, 50\% disagreed), mainly as they did not see it as their junior staff's job, (50\% agreed, $20 \%$ disagreed). Forty per cent thought that near patient testing improved the outcome for patients compared with $18 \%$ who disagreed. However, this question elicted the largest uncommitted response $(43 \%)$ reflecting the position that this point has not been tested scientifically. Respondents did not see their tests being done at the bedside in future and preferred to have results phoned to them, rather than have to look them up on a computer screen. There was some support for near patient testing in the intensive care units or for a "hot" laboratory facility next to these units. This concept received support particularly from the clinicians working in intensive care, although some suggested that it was only necessary to have a blood gas analyser on the ward with all other analyses being performed remotely in the main laboratory linked by a tube transport system.

\section{SAMPLE TRANSPORT}

Sample transport to the laboratories was clearly identified as a problem in obtaining a rapid response. Sixteen (59\%) hospitals either possessed tube transport systems or were installing one. In most cases these were linked to only a few sites in the hospital but a few had more comprehensive systems linking the acute areas and the laboratories. Unsolicited comments from those without such systems revealed the considerable amount of frustration for laboratory and clinical staff generated by the problems of getting samples to the laboratory quickly. On the main questionnaire, the statement suggesting that a good laboratory response eliminated the need for near patient testing was echoed in many of the final comments; however, there were many references to the difficulties junior staff found in contacting the laboratory or getting the sample there.

\section{Discussion}

These results support the evidence from Pathology laboratories throughout the country that there is considerable demand for urgent tests from acute clinical areas. Figures for the department of clinical chemistry from the pilot hospital showed that demand represents up to $20 \%$ of the laboratory workload on some days. In this survey, clinicians requesting very large numbers of tests per day tended to work in acute ward areas (for example, estimates of 100 blood gases per day from a large intensive care unit and 100 blood glucose estimations a day from a diabetic inpatient ward). Nevertheless, the median figures accord with the experience of laboratories receiving these requests.

There is no doubt about the place of near patient testing in some settings such as the intensive care unit where information from blood gas analysis is used in adjusting ventilator settings, or diabetic wards where blood glucose measurements are essential in monitoring diabetics. Indeed, in this survey, the largest 
demand came from intensive care, neonatal care and diabetic wards. However, there is no evidence that near patient testing provides positive patient benefits when compared with sending samples for rapid central laboratory analysis. One study from America indicated that patient outcomes may be worse if analyses of critical tests are performed by physicians' office laboratories performing few tests on a regular basis rather than central laboratories. ${ }^{4}$ Even in the accident and emergency department where near patient testing might be expected to have an impact, this has not been borne out by detailed study. ${ }^{5}$ Most clinicians cited the need for speed as their reason for using bedside testing, but no attempt was made in this questionnaire to ask them to justify their need for urgency for the wide range of tests mentioned. Surprisingly, patient management did not figure prominently in the reasons given. Despite this, consultants were cautious about using the results of near patient testing for patient management, even if they can be obtained quickly, where as the most positive statement by all respondents was that they trusted their local laboratory results. Indeed, $44 \%$ would not accept responsibility for a near patient test result. The latter point suggests that there is a need to define clearly the line of accountability for near patient testing.

The concern shown by a significant number of clinicians in this survey about the quality of the results of near patient testing is justified. Two hazard warnings have been issued about near patient testing equipment, ${ }^{67}$ drawing attention to the need for adequate management supervision and quality control procedures when operating such equipment. A study ${ }^{8}$ undertaken in 1986 in one of the regions surveyed revealed that quality control procedures and training of users were undertaken in connection with fewer than $50 \%$ of sites with blood gas analysers and $25 \%$ of sites with blood glucose meters. The situation had improved considerably in $1993^{\circ}$ and currently $100 \%$ of laboratories are involved with near patient testing instruments in that region (D Freedman, personal communication). This situation is not universal, however, as a national survey of intensive care facilities showed that nearly half of the units did not consult their biochemistry department regarding equipment choice or methodology, and $30 \%$ of intensive care laboratories performed no quality control. ${ }^{10}$ In this survey, although $46 \%$ believed their staff were appropriately trained for near patient testing, 37\% did not know and significantly fewer (24\%) thought their performance was monitored regularly, an essential part of quality assurance.

Quality assurance of central laboratory analytical services is now being tested by laboratory accreditation. ${ }^{11}$ This covers all aspects of the laboratory service including management, staff training, procedures and protocols, health and safety, as well as formal quality assessment procedures. In principle, quality assurance of near patient testing should follow the same standards, in that staff should be trained to perform the tests, operating and reporting pro- cedures should be documented and followed, and there should be a regular programme of internal and external quality assurance. A number of codes of practice have been drawn up to provide guidance. ${ }^{12-16} \mathrm{~A}$ key feature of these codes of practice is the commitment to training, monitoring and continuing education of all operators, regular quality assurance programmes and limitation on usage to certified operators. These operational issues affect many staff groups and this should be reflected in a coherent management stance on near patient testing across the hospital. ${ }^{17}$

Providing appropriate near patient testing does cost more than the simple cost of test strips or other consumables and may be comparable with or more expensive than using central laboratories. ${ }^{18-20}$ There are currently no data as to whether near patient testing is costeffective in hospitals, although in general practice where there are inevitably considerable delays in obtaining laboratory results from hospital tests, one major study showed that even here, near patient testing was only cost-effective for screening for urinary tract infection. ${ }^{21}$

The main frustration in obtaining a rapid result for both the clinicians and laboratories was in the transport of samples to the laboratory. Although most hospitals had a tube transport system, this was not comprehensive in most of them. Demand for near patient tests may be a response to this transport problem and reflect the lack of investment in hospital infrastructure. Of staff who expressed a preference, $71 \%$ indicated they would not need near patient testing if rapid transport were available, $79 \%$ saying that this was the biggest problem with urgent tests. This indicates a strong preference among clinicians for rapid transport systems and central laboratory analysis rather than bedside testing. The Audit Commission in its report, Critical Path, ${ }^{22}$ drew similar conclusions with respect to pathology services as a whole, identifying sample transport and report delivery as major deficiencies, often being outside the control of the laboratory. The weakness of near patient testing as a solution to $D$ this problem is highlighted by the Standing Group on Health Technology which identified $\tilde{N}$ near patient testing as one of the early projects in its assessment programme. ${ }^{23}$

Our study clearly confirms the apparent need for rapid response testing but poses many questions with regard to the clinical and cost-effectiveness of a near patient testing solu- 吕 tion. Our study identifies the need for the investigation of a wide range of issues related to near patient testing; these include:

- The cost-effectiveness of full quality assurance programmes for ward based testing which will include determination of the true costs of quality control and operator training, certification and continuing education.

- The clinical and cost-effectiveness of rapid response testing for a range of analyses-for example, urea and electrolytes, blood gases, lactate, therapeutic drugs, blood glucose, in clinical areas such as accident and emergency, intensive care and neonatal intensive 
care, general medical wards and specialist outpatient clinics.

- Identification of response times in relation to clinical need and the comparative value and costs for rapid sample transport and near patient testing.

Finally, while this study has raised several important questions regarding the need for rapid response testing and highlighted to the absence of evidence in support of its clinical and cost-effectiveness, it has not addressed the wider issues that may influence the successful exploitation of near patient testing. The rapid availability of results is only of real value if action is taken immediately. Such action may involve institution of a particular therapeutic strategy which has clinical or operational benefit-for example, prompt a further investigation, the discharge of the patient, or initiation of a particular treatment. The effort involved in obtaining a rapid result is wasted if the result is not seen and acted on promptly.

1 Marks V. Clinical Biochemistry nearer the patient. $B M \mathcal{F}$ 1983;286: 1166-7.

2 Marks V, Alberti KGMM (eds). In: Clinical biochemistry nearer the patient. Edinburgh: Churchill Livingstone, 1985.

3 Lathrop JP. The patient-focused hospital. Health C Forum $\mathcal{f}$ 1991;34:17-21.

4 Mennemeyer ST, Winkelman JW. Searching for inaccuracy in clinical laboratory testing using Medicare data: evidence for prothrombin time. $\mathcal{F A M} A$ 1993;269:1030-3.

5 Parvin CA, Lo SF, Deuser SM, et al. Impact of point-of-care testing on patients' length of stay in a large emergency department. Clin Chem 1996;42:711-17.

6 Department of Health and Social Security. Blood glucose measurements: reliability of results produced in extralaboratory areas. $\mathrm{HN}(\mathrm{Hazard})(87) 13$

7 Department of Health. Blood gas measurements: The need for reliability of results produced in extra-laboratory areas. HC(Hazard) (89) 31 .
8 Burrin JM, Fyffe JA. Diagnostic equipment outside the laboratory. $\mathcal{F}$ Clin Pathol 1988;41:925-8.

9 Freedman DB, Stevens J. Audit of near patient testing in North West Thames. Proceedings of the ACB National Meeting 1994:74-5.

10 Cox DJA, Naidoo R. The intensive care laboratoryreport of current UK practice and recommendations fo the implementation of required minimum standards. Care Crit Ill 1995;11:98-103.

11 Clinical Pathology Accreditation (UK) Ltd. The CPA accreditation handbook. Sheffield: Clinical Pathology Accreditation (UK) Ltd, 1992.

12 Dybkaer R, Martin DV, Rowan RM (eds). Good practice in decentralised analytical clinical measurement. Scand $7 \mathrm{Clin}$ Lab Invest 1992;52(Suppl 209): 1-116.

13 Association of Clinical Biochemists. Guidelines for implementation of near patient testing. London: Association of Clinical Biochemists, 1993.

14 Joint Working Group on Quality Assurance. Guidelines on the control of near patient tests (NPT) and procedure performed on patients by non-Pathology staff. Bull Roy Coll Pathol 1993;81:22-3.

15 Welsh Scientific Advisory Committee. Near patient testing The use of diagnostic equipment and procedures outside the diagnostic laboratory. Cardiff: Welsh Office, 1995.

16 Price CP, Burrin JM, Nattrass M. Extra-laboratory blood glucose measurement: A policy statement. Diab Med 1988; 5:705-9.

7 Burnett D, Freedman D. Near-patient testing: The management issues. Health Service Management 1994;March:10-13.

18 Winkelman JW, Wybenga DR, Tanasijevic MJ. The fiscal consequences of central vs distributed testing of glucose. Clin Chem 1994;40:1628-30.

19 Greendyke RM. Cost analysis: Bedside blood glucose testing. Am f Clin Pathol 1992;97:106-7.

20 Lee-Lewandrowski E, Laposata M, Eschenbach $\mathrm{K}$, Ca mooso C, Nathan DM, Godine JE, et al. Utilisation and cost analysis of bedside capillary glucose testing in a large teaching hospital: Implications for managing point of care testing. Am f Med 1994;97:222-30.

21 Rink E, Hilton S, Szczepura A, Fletcher J, Sibbald B, Davies C et al. Impact of introducing near patient testing for standard investigations in general practice. BMf 1993;307:775-8.

22 Audit Commission. Critical Path: An analysis of Pathology services. Audit Commission, National Health Servic Report No 8. London: HMSO, 1993.

23 Standing Group on Health Technology. Initial priorities for Health Technology assessment. Annex 5: First Report to the Central Research and Development Committee nology. December 1993. 